УДК 620.197.5:622.692.4.053

РАСЧЕТ ОПТИМАЛЬНЫХ РЕЖИМОВ РАБОТЫ УСТАНОВОК КАТОДНОЙ ЗАЩИТЫ МАГИСТРАЛЬНОГО НЕФТЕПРОВОДА

\title{
CALCULATION OF OPTIMAL OPERATING MODES \\ OF STATIONS CATHODIC PROTECTION OF THE MAIN OIL PIPELINE
}

\section{Николай Николаевич Скуридин ${ }^{1}$, Антон Сергеевич Тюсенков ${ }^{2}$, Дмитрий Ефимович Бугай}

${ }^{1}$ ООО «НИИ Транснефть», Москва, Россия

${ }^{2}$ Уфимский государственный нефтяной технический университет, Уфа, Россия

\author{
Nikolay N. Skuridin ${ }^{1}$, Anton S. Tyusenkov ${ }^{2}$, Dmitry E. Bugai ${ }^{2}$ \\ ${ }^{1}$ Pipeline Transport Institute, LLC, Moscow, Russia \\ ${ }^{2}$ Ufa State Petroleum Technological University, Ufa, Russia
}

Аннотация. Коррозионные поражения металла являются одним из основных факторов, снижающих безопасность эксплуатации магистральных трубопроводов. Известно, что около $70 \%$ отказов нефтепроводов происходит вследствие коррозии металла. Электрохимическая защита в комплексе с неметаллическими покрытиями является в настоящее время основным способом, предотвращающим агрессивное воздействие коррозионно-активных сред на магистральные трубопроводы.

Применение данных способов защиты трубопроводов имеет ряд трудностей, которые могут быть связаны с использованием на одном нефтепроводе нескольких защитных покрытий разного типа и состояния; применением катодных станций различной конструкции и эффективности; 
отсутствием системы, позволяющей проводить мониторинг объектов электрохимической защиты; сложностями, возникающими при эксплуатации анодных заземлителей и электродов сравнения.

В этих условиях приведение технического состояния системы антикоррозионной защиты магистральных нефтепроводов к уровню, соответствующему современным требованием промышленной безопасности, оказывается важной задачей, позволяющей повысить безопасность и надежность объектов трубопроводного транспорта.

В статье приводится анализ работы установок катодной защиты магистрального нефтепровода Калтасы - Языково и результаты расчетов по оптимизации режимов работы катодных станций.

Abstract. Corrosion damage to metal is one of the main factors that reduce the safety of operation of main pipelines. It is known that about $70 \%$ of pipeline failures are due to metal corrosion. Electrochemical protection in combination with non-metallic coatings is currently the main method to prevent the aggressive effect of corrosive media on trunk pipelines.

The use of these methods of protecting pipelines has a number of difficulties, which can be associated with the use of several protective coatings of different types and conditions on one oil pipeline; the use of cathode stations of various designs and efficiency; lack of a system that allows monitoring objects of electrochemical protection; difficulties arising during the operation of anode grounding electrodes and reference electrodes.

Under these conditions, bringing the technical state of the anticorrosion protection system of main oil pipelines to a level corresponding to the modern requirements of industrial safety turns out to be an important task that makes it possible to increase the safety and reliability of pipeline transport facilities.

The article provides an analysis of the operation of cathodic protection installations of the Kaltasy - Yazykovo main oil pipeline and the results of calculations to optimize the operating modes of cathode stations. 
Ключевые слова: магистральный нефтепровод, коррозия, сталь, электрохимическая защита, катодная защита, катодная станция, защитный потенциал, пожарный риск

Keywords: pipeline, corrosion, steel, electrochemical protection, cathode protection, cathode station, protective potential, fire risk

\section{Введение}

Как известно $[1,2]$, защищенность нефтепровода от коррозии во многом зависит от значения поляризационного потенциала его поверхности, который, в свою очередь, определяющим образом влияет на кинетику электродных реакций в почвенных электролитах. Метод катодной защиты обеспечивает кардинальное снижение скорости коррозии металла нефтепровода вследствие обращения защищаемой поверхности в неразрушающийся катод. При смещении электродного потенциала из оптимального диапазона электрохимзащиты (ЭХЗ) - 0,85-1,15 В (по м.с.э.) коррозионные процессы существенно промотируются. С уменьшением абсолютного значения потенциала развивается локальная коррозия (местная, язвенная), с увеличением - отслаивание покрытий и, как следствие, проникновение агрессивной среды в образовавшиеся пустоты [3-6].

В настоящее время требует существенной доработки методика расчёта оптимального режима работы установок катодной защиты на многониточных нефтепроводах, имеющих различные свойства защитных покрытий (переходное сопротивление, сплошность). В связи с этим существует вероятность «перезащиты» или «недозащиты» нефтепроводов, проходящих в одном техническом коридоре с другими магистральными нефтепроводами и нефтепроводами-отводами или их участками. Кроме того, эффективность систем электрохимзащиты снижается из-за того, что управление станциями катодной защиты в большинстве случаев осуществляется за счет поддержания заданных параметров работы без их адаптации к изменяющимся условиям 
нагрузки. В подобных условиях сложно устанавливать оптимальные выходные режимы работы установок катодной защиты (УКЗ), которые обеспечивали бы надежную защиту металла на всем протяжении магистрального нефтепровода с учетом изменяющихся во времени внешних факторов (удельное сопротивление грунта, режимы работы смежных станций катодной защиты, наличие блуждающих токов, плотность постоянного и переменного тока, температура).

\section{Методика эксперимента}

Эффективное функционирование системы электрохимзащиты возможно только при корректном учете коррозионного состояния магистрального нефтепровода и разработки компенсирующих мероприятий на основе анализа данных внутритрубной диагностики. С этой целью представляется перспективным использование системы ранжирования участков магистрального нефтепровода по степени коррозионной опасности. Например, участки с высокой коррозионной опасностью характеризуются скоростью коррозии свыше 0,5 мм/год, либо язвами и трещинами, глубина которых превышает 15 \% толщины стенки трубопровода. Эти участки подлежат первоочередному ремонту. Участки трубопровода, скорость коррозии металла которых составляет 0,3-0,5 мм/год, либо на которых имеются трещины и язвы глубиной более 10 \% толщины стенки трубы, относят к участкам повышенной коррозионной опасности. Эти участки должны быть отремонтированы во вторую очередь [7].

В случае отсутствия возможности снизить скорость разрушения на участках с высокой коррозионной опасностью до нормативных значений, требуются компенсирующие мероприятия, заключающиеся в установке дополнительных станций катодной защиты, либо замене используемых станций на более мощные. Также может потребоваться замена поврежденного участка магистрального нефтепровода. 
Расчет оптимальных режимов работы УКЗ проводили для линейного участка магистрального нефтепровода Калтасы - Языково.

Математическая модель процессов работы средств электрохимической защиты основана на методе конечных элементов, что позволяет учитывать в расчетах неоднородность защитного покрытия, параметры нефтепровода и коррозионной среды.

Алгоритм расчета оптимальных токов УКЗ основан на численном методе сопряженных градиентов для нелинейных функций и методов Левенберга-Марквардта и квазиньютоновских методов [8]. На основании сравнения рассчитанных в программе и фактически измеренных токов станций катодной защиты осуществлялся анализ функционирования системы ЭХЗ выбранного участка магистрального нефтепровода.

Исходными данными для расчета являлись значения удельного сопротивления грунта по трассе нефтепровода, переходного сопротивления защитного покрытия, защитных потенциалов, измеренных через каждые 10 м, а также естественных потенциалов трубопровода, измеренных на контрольно-измерительных пунктах.

\section{Результаты расчетов и их обсуждение}

Расчеты токов УКЗ выполняли в два этапа:

- анализ параметров работы станций катодной защиты на основании сравнения выходных значений фактических и расчетных токов защиты;

- оптимизация режимов работы катодных станций с помощью расчета выходных параметров, обеспечивающих значения защитных потенциалов по всей длине трубопровода в диапазоне допускаемых значений.

Проводились также необходимые расчеты по формированию и выводу в табличном виде основных расчетных параметров установок катодной защиты (таблица 1), включающих ток УКЗ I с учетом влияния заземлений, выходное напряжение УКЗ $U$, мощность УКЗ $W$, входное сопротивление изоляции $Z_{6 x}$ и защитный потенциал в точках дренажа $\varphi_{m \partial .}$ 
Результаты расчетов по анализу режимов работы УКЗ представлены на рисунке 1 в графическом виде.

Таблица 1. Результаты расчета режимов УКЗ

Table 1. The results of calculating the UKZ modes

\begin{tabular}{|c|c|c|c|c|c|c|c|c|c|c|}
\hline $\begin{array}{c}\text { № } \\
\text { УК3 }\end{array}$ & 1 & 2 & 3 & 4 & $4 \mathrm{a}$ & 5 & 6 & $6 \mathrm{a}$ & 7 & 8 \\
\hline$I, \mathrm{~A}$ & 3,86 & 4,61 & 1,83 & 3,56 & 5,03 & 2,74 & 3,36 & 9,06 & 8,41 & 1,51 \\
\hline$U, \mathrm{~B}$ & 8,16 & 1,53 & 3,74 & 6,64 & 19,68 & 6,69 & 17,04 & 43,67 & 8,23 & 2,57 \\
\hline $\begin{array}{c}W, \\
\text { кВТ }\end{array}$ & 0,03 & 0,05 & 0,01 & 0,02 & 0,10 & 0,02 & 0,06 & 0,40 & 0,07 & 0 \\
\hline $\begin{array}{c}Z_{6 x}, \\
\text { Ом }\end{array}$ & 0,14 & 0,14 & 0,4 & 0,23 & 0,18 & 0,30 & 0,26 & 0,08 & 0,06 & 0,57 \\
\hline$\varphi_{m \delta}, \mathrm{B}$ & $-1,06$ & $-1,33$ & $-1,32$ & $-1,36$ & $-1,37$ & $-1,4$ & $-1,51$ & $-1,3$ & $-1,34$ & $-1,42$ \\
\hline
\end{tabular}

Значения естественного потенциала стали $\varphi_{e}$, измеренные на контрольно-измерительных пунктах, составляли минус 0,55 - минус 0,48 В. Пунктирной красной линией показано минимально допустимое значение защитного потенциала за вычетом естественного потенциала.

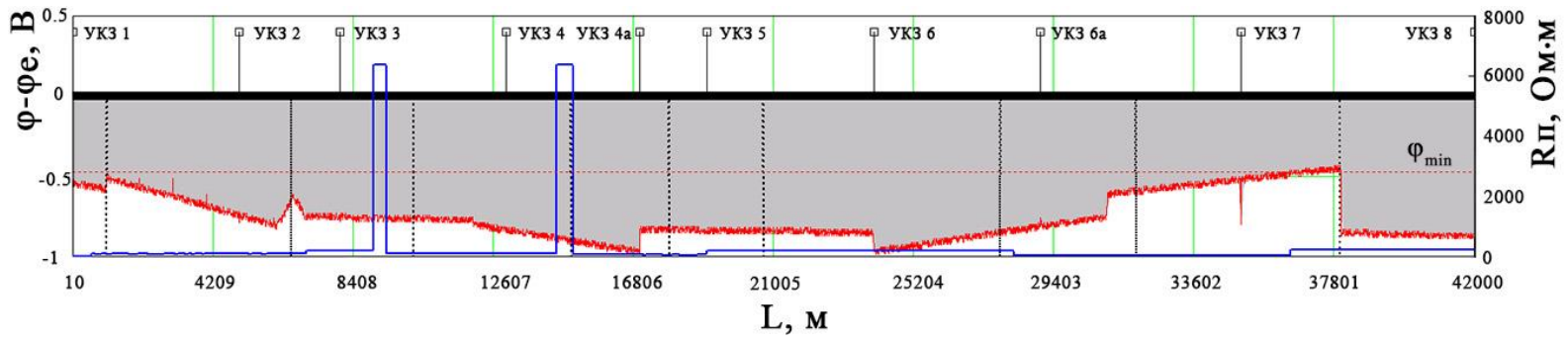

甲 - точки дренажа УКЗ;

mmmer - защитные потенциалы за вычетом естественного потенциала (красная кривая измеренный, серая область - расчетный);

- - переходное сопротивление

里 - drainage points of cathodic protection installations;

manter - protective potentials minus natural potential (red curve - measured, gray area calculated);

- transition resistance

Рисунок 1. Графическое представление результатов расчета

Figure 1. Graphical presentation of calculation results 
Анализ рисунка 1 показывает наличие зоны «недозащиты» на 37,3 км. Разница между расчетными и измеренными на нефтепроводе защитными токами не превышает $15 \%$, что позволяет перейти к определению оптимальных режимов работы УКЗ. С целью реализации надежной защиты выбранного магистрального нефтепровода установили запас минимального абсолютного значения защитного потенциала, равный $20 \%$.

Графическое представление результатов расчетов по оптимизации режимов работы станции катодной защиты приведено в таблице 2 и на рисунке 2. Из рисунка 2 следует, что необходимость в дополнительной станции катодной защиты отсутствует, т.к. существующая система электрохимической защиты способна полностью обеспечить реализацию необходимого расчетного режима работы.

В результате расчетов определены оптимальные значения токов и напряжений УКЗ, минимизирующие потребляемую электроэнергию при обеспечении необходимого уровня защиты.

Анализ полученных данных позволяет очертить круг необходимых компенсирующих мероприятий:

- приведение уровня сопротивления растеканию тока анодных заземлений к нормативному значению;

- установка на катодной станции оптимальных токов защиты и мониторинг уровня защитных потенциалов с помощью контрольноизмерительных приборов.

Таблица 2. Результаты расчета по оптимизации режимов работы УКЗ

Table 2. Calculation results for optimization of operating modes of cathodic protection installations

\begin{tabular}{|c|c|c|c|c|c|c|c|c|c|c|}
\hline № УК3 & 1 & 2 & 3 & 4 & $4 \mathrm{a}$ & 5 & 6 & $6 \mathrm{a}$ & 7 & 8 \\
\hline$I, \mathrm{~A}$ & 0,99 & 5,36 & 0,43 & 5,61 & 1,52 & 4,60 & 0,65 & 9,80 & 10,73 & 0,96 \\
\hline$U, \mathrm{~B}$ & 2,17 & 12,14 & 1,15 & 9,88 & 6,40 & 10,47 & 3,38 & 47,07 & 10,37 & 1,62 \\
\hline$W$, кВт & 0,002 & 0,065 & 0 & 0,055 & 0,010 & 0,048 & 0,002 & 0,461 & 0,111 & 0,002 \\
\hline$Z_{\text {вx }}, \mathrm{OM}$ & 0,213 & 0,128 & 1,041 & 0,124 & 0,287 & 0,138 & 0,446 & 0,067 & 0,053 & 0,549 \\
\hline$\varphi_{m д}, \mathrm{~B}$ & $-1,20$ & $-1,41$ & $-1,20$ & $-1,41$ & $-1,20$ & $-1,42$ & $-1,20$ & $-1,38$ & $-1,31$ & $-1,24$ \\
\hline
\end{tabular}




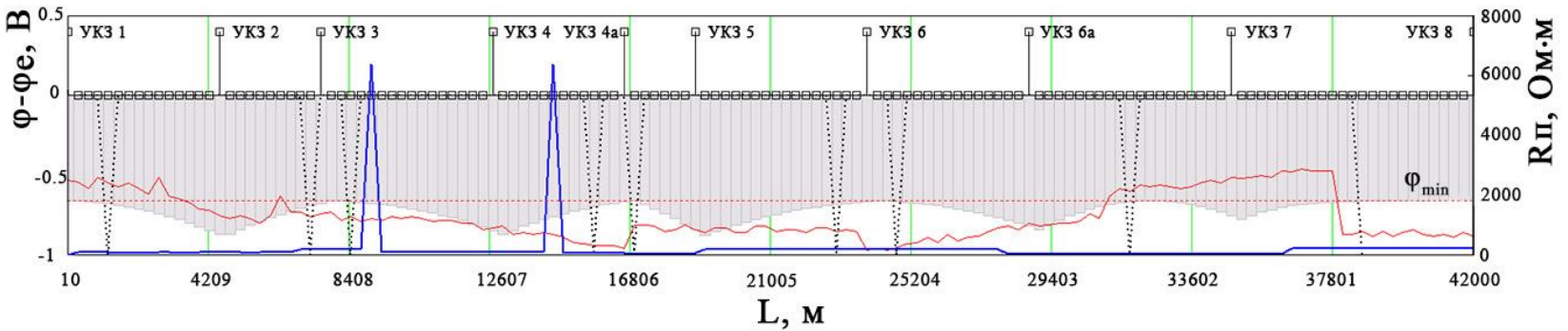

Рисунок 2. Графическое представление результатов оптимизации режимов работы станции катодной защиты (обозначения аналогичны рисунку 1)

Figure 2. Graphical presentation of the results of optimization of the operating modes of the cathodic protection station (designations are similar to Figure 1)

Таким образом, расчетами установлена необходимость увеличения тока 8- й УКЗ до 17,7 А и напряжения до 20,9 В, что позволит исключить зону «недозащиты» на 37,3 км. Также скорректированы значения токов остальных установок катодной защиты.

Проведенная в дальнейшем апробация разработанных методик показала расхождение результатов расчета и измерений в пределах 10-15\%, что позволяет применять методики для проведения мониторинга функционирования системы электрохимзащиты.

\section{Выводы}

1. Эффективность применения устройств электрохимзащиты снижается вследствие отсутствия адаптации существующих систем управления станциями катодной защиты к изменяющимся условиям нагрузки и учета всех факторов, влияющих на скорость коррозии трубопроводов. В подобных условиях невозможно принять научно обоснованное решение об оптимальных выходных параметрах электрохимической защиты, которые бы полностью обеспечивали защиту магистральных трубопроводов с сохранением минимальных энергозатрат.

2. Предложена методика ранжирования участков магистральных трубопроводов по степени коррозионной опасности, обеспечивающая 
получение необходимой и достаточной информации для выработки последующих компенсирующих мероприятий, которые направлены на обеспечение эффективного функционирования системы электрохимзащиты.

3. Разработана методика расчета режимов работы станций катодной защиты, основанная на определении оптимальных значений токов и напряжений и позволяющая снизить удельную аварийность магистральных нефтепроводов и повысить пожарную и промышленную безопасность их эксплуатации. Методика позволяет определять места рационального расположения станций катодной защиты и точек дренажа с учетом фактического состояния антикоррозионных покрытий магистральных нефтепроводов.

\section{Список источников}

1. Агиней Р.В., Александров Ю.В. Актуальные вопросы защиты от коррозии длительно эксплуатируемых магистральных газонефтепроводов. СПб.: Недра, 2012. 394 с.

2. Гареев А.Г., Насибуллина О.А., Ибрагимов И.Г. Оценка работоспособности труб, имеющих дефекты коррозионного происхождения // Проблемы сбора, подготовки и транспорта нефти и нефтепродуктов. 2016. Вып. 4 (106). С. 126-136.

3. Ризванов Р.Г., Муликов Д.Ш., Каретников Д.В., Черепашкин С.Е., Ширгазина Р.Ф. Коррозионная стойкость сварного соединения узла «трубатрубная решетка», полученного сваркой трением // Нанотехнологии в строительстве: научный интернет-журнал. 2017. Т. 9. № 4. C. 97-115. URL: http://nanobuild.ru/en_EN/journal/Nanobuild-4-2017/97-115.pdf （дата обращения: 21.10.2021). DOI: 10.15828/2075-8545-2017-9-4-97-115.

4. Ахияров Р.Ж., Бугай Д.Е., Лаптев А.Б. Проблемы подготовки оборотных и сточных вод предприятий нефтедобычи // Нефтепромысловое дело. 2008. № 9. С. 61-65. 
5. Гареев А.Г., Насибуллина О.А., Ризванов Р.Г., Хажиев А.Г. Исследование внутренней поверхности трубопровода системы нефтесбора Северо-Красноярского месторождения // Проблемы сбора, подготовки и транспорта нефти и нефтепродуктов. 2016. Вып. 2 (104). С. 58-64.

6. Latypov O.R., Bugai D.E., Boev E.V. Method of Controlling Electrochemical Parameters of Oil Industry Processing Liquids // Chemical and Petroleum Engineering. 2015. Vol. 51. P. 283-285. DOI: 10.1007/s10556-0150038-8.

7. Скуридин Н.Н. Методический подход к оценке степени коррозионной опасности участков магистральных нефтепроводов по данным внутритрубной диагностики // Наука и технологии трубопроводного транспорта нефти и нефтепродуктов. 2012. № 4 (8). С. 99-101.

8. Скуридин Н.Н., Корзинин В.Ю., Бороденко Д.В. Апробация методов статистической обработки данных коррозионных обследований и внутритрубной диагностики для оценки коррозионного состояния МН ОАО ««АК «Транснефть»// Наука и технологии трубопроводного транспорта нефти и нефтепродуктов. 2015. № 1 (17). С. 74-79.

\section{References}

1. Aginei R.V., Aleksandrov Yu.V. Aktual'nye voprosy zashchity ot korrozii dlitel'no ekspluatiruemykh magistral'nykh gazonefteprovodov [Topical Issues of Corrosion Protection for Long-Term Operating Gas and Oil Trunk Pipelines]. St. Petersburg, Nedra Publ., 2012. 394 p. [in Russian].

2. Gareev A.G., Nasibullina O.A., Ibragimov I.G. Otsenka rabotosposobnosti trub, imeyushchikh defekty korrozionnogo proiskhozhdeniya [Evaluation of the Performance of Pipes with Corrosion Defects]. Problemy sbora, podgotovki $i$ transporta nefti $i$ nefteproduktov - Problems of Gathering, Treatment and Transportation of Oil and Oil Products, 2016, Issue 4 (106), pp. 126-136. [in Russian]. 
3. Rizvanov R.G., Mulikov D.Sh., Karetnikov D.V., Cherepashkin S.E., Shirgazina R.F. Korrozionnaya stoikost' svarnogo soedineniya uzla «trubatrubnaya reshetka», poluchennogo svarkoi treniem [Corrosion Resistance of «Tube-Tubesheet» Weld Joint Obtained by Friction Welding]. Nanotekhnologii v stroitel'stve: nauchnyi internet-zhurnal - Nanotechnologies in Construction: A Scientific Internet-Journal, 2017, Vol. 9, No. 4, pp. 97-115. URL: http://nanobuild.ru/en_EN/journal/Nanobuild-4-2017/97-115.pdf (accessed 21.10.2021). DOI: 10.15828/2075-8545-2017-9-4-97-115. [in Russian].

4. Akhiyarov R.Zh., Bugai D.E., Laptev A.B. Problemy podgotovki oborotnykh i stochnykh vod predpriyatii neftedobychi [Problems of Treatment of Circulating and Waste Waters of Oil Production Enterprises]. Neftepromyslovoe delo - Oilfield Engineering, 2008, No. 9, pp. 61-65. [in Russian].

5. Gareev A.G., Nasibullina O.A., Rizvanov R.G., Khazhiev A.G. Issledovanie vnutrennei poverkhnosti truboprovoda sistemy neftesbora SeveroKrasnoyarskogo mestorozhdeniya [Study of the Inner Surface of the Oil Gathering Pipeline in the Northern Krasnoyarsk Field]. Problemy sbora, podgotovki i transporta nefti i nefteproduktov - Problems of Gathering, Treatment and Transportation of Oil and Oil Products, 2016, Issue 2 (104), pp. 58-64. [in Russian].

6. Latypov O.R., Bugai D.E., Boev E.V. Method of Controlling Electrochemical Parameters of Oil Industry Processing Liquids. Chemical and Petroleum Engineering, 2015, Vol. 51, pp. 283-285. DOI: 10.1007/s10556-0150038-8.

7. Skuridin N.N. Metodicheskii podkhod k otsenke stepeni korrozionnoi opasnosti uchastkov magistral'nykh nefteprovodov po dannym vnutritrubnoi diagnostiki [Methodical Approach to Assessing the Corrosion Hazard Areas of Pipelines According to the Trunk Pipeline Pigging]. Nauka i tekhnologii truboprovodnogo transporta nefti i nefteproduktov - Science and Technologies: Oil and Oil Products Pipeline Transportation, 2012, No. 4 (8), pp. 99-101. [in Russian]. 
8. Skuridin N.N., Korzinin V.Yu., Borodenko D.V. Aprobatsiya metodov statisticheskoi obrabotki dannykh korrozionnykh obsledovanii i vnutritrubnoi diagnostiki dlya otsenki korrozionnogo sostoyaniya MN OAO « «Transneft'» [Testing of the Statistical Data Processing Methods of Corrosion and Inline Inspections for the Corrosion Condition Assessment of JSC «Transneft» Trunk Pipelines]. Nauka $i$ tekhnologii truboprovodnogo transporta nefti $i$ nefteproduktov - Science and Technologies: Oil and Oil Products Pipeline Transportation, 2015, No. 1 (17), pp. 74-79. [in Russian].

\section{Сведения об авторах}

\section{About the Authors}

Скуридин Николай Николаевич, руководитель центра защиты от коррозии, ООО «НИИ Транснефть», Москва, Россия

Nikolay N. Skuridin, Head of Corrosion Protection Center, Pipeline Transport Institute, Moscow, Russia

e-mail: skuridinnn@niitnn.transneft.ru

Тюсенков Антон Сергеевич, канд. техн. наук, доцент кафедры «Материаловедение и защита от коррозии», УГНТУ, Уфа, Россия

Anton S. Tyusenkov, Candidate of Engineering Sciences, Assistant Professor of Materials and Corrosion Protection Department, USPTU, Ufa, Russia e-mail: anton.tyusenkov@yandex.ru

Бугай Дмитрий Ефимович, д-р техн. наук, профессор кафедры «Материаловедение и защита от коррозии», УГНТУ, Уфа, Россия

Dmitry E. Bugai, Doctor of Engineering Sciences, Professor of Materials and Corrosion Protection Department, USPTU, Ufa, Russia e-mail: debugai@mail.ru 